\title{
História e memória da Escola Normal Helvídio Nunes de Barros (Bom Jesus, Piauí)
}

History and memory of the Normal School Helvídio Nunes de Barros (Bom Jesus, Piauí)

Historia y memoria de la Escuela Normal Helvídio Nunes de Barros (Bom Jesus, Piauí)

\author{
Lia Machado Fiuza Fialho \\ Universidade Estadual do Ceará (Brasil) \\ http://lattes.cnpq.br/4614894191113114 \\ http://orcid.org/0000-0003-0393-9892 \\ lia_fialho@yahoo.com.br \\ Maria Aparecida Alves da Costa \\ Universidade Estadual do Ceará (Brasil) \\ http://lattes.cnpq.br/3305904539863361 \\ https://orcid.org/0000-0001-5213-4869 \\ mariapedagoga99@gmail.com
}

\section{Resumo}

O artigo relata a história da Escola Normal Helvídio Nunes de Barros, localizada na cidade de Bom Jesus, Piauí, o educandário é pioneiro na região na oferta do Ensino Normal. Objetivouse desvelar uma narrativa histórica acerca da escola na sua inter-relação com o contexto educacional de Bom Jesus na década 1970. Com base nos pressupostos da História Cultural e metodologicamente na História Oral, com três colaboradores que vivenciaram o período de fundação da escola - professor e diretor Dom Ramón, supervisora Ivanilde Borges e aluna Ecileide Martins -, entrecruzada com fontes documentais - regimento interno da escola e Resolução do Conselho Estadual de Educação n. 4/1970 -, foi desenvolvida uma pesquisa que constatou que o surgimento da mencionada instituição foi decorrente da ampliação do acesso à educação, bem como do número de escolas primárias na região sul do Piauí, o que demandou formação específica para o magistério a fim de substituir os professores leigos.

Palavras-chave: História. Memória. Escola Normal Helvídio Nunes de Barros. 


\begin{abstract}
The article reports the history of Escola Normal Helvídio Nunes de Barros. The college is located in Bom Jesus city, in the state of Piauí, and is a pioneer in the region concerning Normal education. The aim was to unveil a historical narrative about the school in its interrelationship with the educational context of Bom Jesus city in the 1970s. Based on the premises of Cultural History and methodologically on Oral History, with three contributors who experienced the founding period of the school - teacher and principal Dom Ramón, supervisor Ivanilde Borges and the student Ecileide Martins -, cross-checked with documentary sources - the school's internal guidelines and Resolution CEE/04/70. The research verified that the emergence of the aforementioned institution happened due to the expansion of access to education, as well as the number of primary schools in the southern region of Piauí, which required specific teacher training in order to replace lay teachers.
\end{abstract}

Keywords: History. Memory. Normal School Helvídio Nunes de Barros.

\title{
Resumen
}

El artículo trata sobre la historia de la Escola Normal Helvídio Nunes de Barros, localizada en Bom Jesus, Piauí, pionera en la región en la provisión de educación normal. El objetivo es revelar una narración histórica sobre la escuela en su interrelación con el contexto educativo de la ciudad de Bom Jesus en la década de 1970. Basado en los supuestos de la Historia Cultural y metodológicamente en la Historia Oral, con tres colaboradores que vivieron el período de fundación de la Escuela - maestro y director Don Ramón, supervisora Ivanilde Borges y estudiante Ecileide Martins -, entrelazados con fuentes documentales - el reglamento interno escolar y la Resolución del Consejo Estatal de Educación n. 4/1970 -, se desarroló una investigación que constató que el surgimiento de la referida escuela fue el resultado de la expansión del acceso a la educación, así como el aumento del número de escuelas primarias en la región sur de Piauí, que requirió capacitación específica para la profesión docente para reemplazar a los maestros legos.

Palabras clave: Historia. Memoria. Escuela Normal Helvídio Nunes de Barros. 


\section{Introdução}

A pesquisa científica em tela inter-relaciona duas áreas coexistentes, História e Educação, ao se inserir no campo da História da Educação (VASCONCELOS; FIALHO; MACHADO, 2018) e mais especificamente trabalha com a história de instituições (GATTI JÚNIOR, 2002; MAGALHÃES, 2005; SOUZA; LIMA, 2016; SANFELICE, 2006). Versa sobre a Escola Normal Helvídio Nunes de Barros, localizada na cidade de Bom Jesus, Piauí, objeto de estudo desta investigação.

A mencionada escola foi a primeira instituição fundada na região sul do Piauí destinada a formar professores, no entanto possuía caráter elitista, porque, mesmo vinculada à Igreja Católica, cobrava mensalidades não acessíveis para a maior parte da população local. Dessa maneira, ao tempo que excluía o acesso aos menos favorecidos economicamente, a escola era responsável pela educação de boa parte da população mais abastada, em especial de pessoas da elite, público quase exclusivo da instituição.

O município de Bom Jesus fica localizado no sul do estado do Piauí, situado no Vale do Rio Gurgueia, cerca de 635 quilômetros de Teresina, capital do estado, possuindo aproximadamente 30 mil habitantes. É um município caracterizado por ser rico em água e por ter terreno fértil para o fomento do agronegócio ${ }^{1}$ se comparado a outros municípios do estado, além de se destacar pela produção de soja e mel, uma das maiores fontes de renda do Piaú, contudo a cidade conta com problemas sociais, a exemplo do desemprego, que leva muitas famílias a sobreviverem por meio de programas sociais, como o Programa Bolsa Família, assim como a falta de infraestrutura urbana, a exemplo da ausência de saneamento e transporte público (IBGE, 2018).

No tocante ao cenário educacional, até a década de 1970, o sul do Piauí apresentava altos índices de analfabetismo decorrentes majoritariamente da carência de instituições públicas de ensino e do fato de as crianças e jovens trabalharem na agricultura para colaborar com o sustento da família. $\mathrm{O}$ acesso ao ensino secundário era restrito às camadas favorecidas economicamente porque era fomentado apenas em uma instituição, denominada Ginásio Odilon Parente, que, além de ser paga, aplicava severo exame de admissão. Esse tipo de exame era comum para restringir o acesso ao Ginasial, já que não havia vagas para atender à demanda total de alunos (ABREU; MINHOTO, 2012).

Com a chegada da Ordem Mercedária ${ }^{2}$, por intermédio do Bispo Dom José Vázquez Díaz, iniciou-se uma preocupação prioritária com a educação da população, mediante a qual se influenciava socialmente as pessoas para conhecer, acreditar e se comportar consoante os preceitos cristãos (TEIXEIRA, 2017). A ordem gerenciada por Dom Vázquez fundou algumas "escolas-comércios" e "escolas primárias" em comunidades rurais pertencentes ao Centro Educacional Diocesano, bem como outras duas escolas que possuíam o ensino secundário: a Escola Normal Helvídio Nunes de Barros e o Curso Científico Dom José Vázquez Díaz. Além disso, o governo do Piauí iniciou, a partir de 1990, a expansão de algumas escolas secundárias, como a Unidade Escolar Araci Lustosa e a Unidade Escolar Joaquim Parente, localizadas também em Bom Jesus (NOVO, 2017).

Com a ampliação do agronegócio, o município foi crescendo economicamente; em paralelo, o fomento à educação empreendido inicialmente pela Ordem Mercedária e posteriormente pelo estado ampliava a escolarização da população bonjesuense, em especial dos que podiam usufruir de tempo para se dedicar aos estudos em vez de estar trabalhando na agricultura para ajudar no sustento da casa (RAPOSO, 2004).

\footnotetext{
${ }^{1}$ O agronegócio vem da palavra em inglês "agribusiness" e representa o conjunto de atividades agrícolas e industriais no caminho do campo ao consumidor final. Hoje o agronegócio está entre os maiores geradores de emprego no mundo.

${ }^{2}$ Ordem religiosa de origem espanhola que chegou em Bom Jesus no ano de 1956 com o Bispo Dom José Vázquez Díaz.
} 
Nesta pesquisa, no entanto, questionou-se como se deu a constituição da Escola Normal Helvídio Nunes de Barros no contexto educacional de Bom Jesus. Para responder a essa inquietação, desenvolveu-se um estudo com o objetivo de desvelar uma narrativa histórica acerca da Escola Normal Helvídio Nunes de Barros na sua inter-relação com o cenário educacional da cidade de Bom Jesus na década de 1970. A delimitação temporal estabelecida se justifica pelo fato de a escola ter sido inaugurada em 1970, ano em que foi fundada e quando se iniciaram suas atividades educativas.

A relevância em estudar a história de instituições escolares consiste em desvelar possibilidades de análises sobre o passado e o presente do cenário educacional, permitindo ampliar a compreensão acerca do processo de mudança social, cultural e educacional em um determinado tempo e espaço (FIALHO, SÁ, 2018). Afinal, “[...] a história das instituições educativas tem melhorado no contexto dos estudos de história da educação no Brasil, renovando o campo da história da educação e organizando-se como um novo campo temático da historiografia da educação brasileira" (GATTI JÚNIOR, 2002, p. 19).

Vale esclarecer que, mesmo na condição de campo consolidado, os estudos sobre instituições educativas não conseguiram ainda registrar a história e memória de importantes edificações educativas, como, por exemplo, a Escola Normal Helvídio Nunes de Barros, estabelecimento educacional que marcou a história da educação e da formação de professores da região sul do estado do Piauí, fundada em 1970 e extinta em 2001, após 31 anos de funcionamento. Não houve preservação arquitetônica provavelmente pelo fato de não possuir um prédio próprio e funcionar em diferentes edificações, como nas dependências da diocese Bom Jesus, no $2^{\circ}$ andar da catedral, e depois no prédio do Seminário Maior, que, inclusive, em 2019, foi alugado para uma escola privada de Educação Infantil e Ensino Fundamental.

A Escola Normal Helvídio Nunes de Barros também não galgou visibilidade nas pesquisas acadêmicas, já que não se localizam estudos sobre a referida instituição nas principais bases de dados científicas do Brasil. Essa afirmação foi possível desde uma busca realizada no mês de janeiro de 2019 para identificar possíveis estudos prévios concernentes à Escola Normal Helvídio Nunes de Barros. Realizou-se a busca no Portal de Periódicos do Centro de Aperfeiçoamento de Pessoal de Ensino Superior (Capes), na base de dados Scientific Eletronic Library Online (Scielo) e na Biblioteca Digital de Teses e Dissertações (BDTD) com os seguintes descritores: "Escola Normal de Bom Jesus" e "Escola Normal Helvídio Nunes de Barros". O único achado foi um resumo de dissertação no BDTD da Universidade Federal do Piauí (UFPI), intitulada A Ordem Mercedária e a educação no Piauí: Escola Normal Helvídio Nunes de Barros, porém o trabalho completo nunca esteve disponível. Em contato efetivado com a Biblioteca do Programa de Pós-Graduação em Educação (PPGE) da UFPI, obtiveram-se informações de que a dissertação foi até defendida, mas o trabalho final ${ }^{3}$ não foi depositado com as alterações sugeridas pela banca.

Para Le Goff (1996, p. 25) “[...] a história é bem a ciência do passado, com a condição de saber que este passado se torna objeto da história por uma reconstrução incessante". Consoante essa ideia, torna-se relevante desvelar a história e memória da Escola Normal Helvídio Nunes de Barros, pois essa (re)constituição permite não apenas entender um objeto de estudo histórico situado no passado, mas sua inter-relação indissociável com o presente e o futuro. No desvelar de narrativas que descortinam, por intermédio de memórias, o cenário educacional do Piauí do fim do século XX, possibilita-se: ampliar a compreensão sobre a história da educação de Bom Jesus, município que carece do registro de narrativas históricas; e refletir sobre a inter-relação da história da instituição com os problemas educacionais ainda vivenciados, a exemplo do número reduzido de escolas existentes de Educação Básica, que é insuficiente para atender à demanda de alunos, especialmente porque há êxodo rural e porque o município recebe

\footnotetext{
${ }^{3} \mathrm{O}$ autor do referido trabalho foi procurado inúmeras vezes, tanto por intermédio do número de telefone concedido pelo PPGE como pelo e-mail registrado na instituição, mas não foi possível localizá-lo.
} 
muitos migrantes de outros lugares circunvizinhos que chegam em busca de melhorias de vida em terras mais férteis (IBGE, 2018).

Com base nos pressupostos da História Cultural (BURKE, 2010), que ampliou a noção de fonte histórica e os objetos de estudos historiográficos, permite-se a valorização de investigações micro-históricas. Esta pesquisa, nessa perspectiva, parte da história de uma única instituição, revelando-se questionadora de um cenário histórico peculiar: o contexto educacional bonjesuense do final do século XX. E, para tal, utiliza como principal procedimento metodológico a História Oral (ALBERTI, 2005; AMADO; FERREIRA, 2006), entrecruzada com outras fontes de cunho documental, como se explicita na próxima seção.

\section{Percurso metodológico}

Partindo da compreensão de que revisitar a história de uma instituição escolar, por meio de memórias, enseja uma riqueza de subjetividades imbricadas nas narrativas da história da educação de um lugar, importa destacar que a memória individual é indissociável da memória coletiva (HALBWACHS, 1993). Ela está relacionada a conhecimentos de mundo, relações sociais, culturas, valores e interpretações distintas, eivadas de subjetividades próprias do ato de narrar o tempo passado, permeadas por lembranças e esquecimentos, propositais ou inconscientes, que possibilitam elaborar enredos históricos variados (POLLAK, 1989) distantes da História única, verdadeira e inquestionável -, considerando a interdisciplinaridade entre as várias ciências e a possibilidade de narrativas diversas. Partindo desse pressuposto, Le Goff (1996, p. 423) acrescenta:

A memória como propriedade de conservar certas informações remetenos em primeiro lugar a um conjunto de funções psíquicas, graças às quais o homem pode atualizar impressões ou informações passadas, ou que ele representa como passadas.

Nesse sentido, revisitou-se a memória da Escola Normal por meio das narrativas de sujeitos que vivenciaram sua educação, considerando os silêncios, as expressões faciais, os esquecimentos e as lembranças rememoradas, afinal compreende-se que a história pode ser tecida a partir de novos sujeitos, novos problemas e novas abordagens (BURKE, 2010), que se distanciam das histórias universais, totalizantes e macrossociais generalizantes.

Como procedimento metodológico, utilizou-se a História Oral Temática por possibilitar um projeto previamente elaborado e entrar em contato com as narrativas de alguns sujeitos que vivenciaram a educação na Escola Normal Helvídio Nunes de Barros durante o tempo de vigência da instituição. Salienta-se, pois, que o trabalho com História Oral "[...] exige do pesquisador um elevado respeito pelo outro, por suas opiniões, atitudes e posições, por sua visão de mundo, enfim. É essa visão de mundo que norteia seu depoimento e que imprime significados aos fatos e acontecimentos narrados" (ALBERTI, 2005, p. 24).

Os colaboradores convidados para participar da pesquisa fornecendo informações desde uma entrevista temática - gravada, transcrita, validada e textualizada - foram selecionados considerando os seguintes critérios de inclusão: profissionais que tivessem vivenciado todo o período de existência da escola e alunos que tivessem iniciado e/ou concluído o curso de magistério nos primeiros anos de funcionamento da instituição. Participaram da pesquisa: o Bispo Dom Ramón López Carrozas, um dos primeiros professores da instituição, que se tornou diretor; a normalista Ivanilde Borges, supervisora da escola; e a professora Ecileide Martins, que também foi aluna nos anos iniciais da escola. A pesquisa seguiu as recomendações da Resolução $\mathrm{n}^{\circ}$ 510, de 07 de abril de 2016, que trata da ética em pesquisas nas áreas de Ciências Humanas e Sociais. Logo, importa esclarecer que a entrevista com o bispo foi cedida pelo pesquisador Ademir 
Martins de Oliveira, as demais foram realizadas após consentimento atestado com a assinatura do termo de consentimento livre e esclarecido, ocasião em se explicou os objetivos da pesquisa, a maneira de participação, a ausência de benefícios diretos, a possibilidade de desistência a qualquer momento e dos possíveis prejuízos - constrangimentos, emoções etc.

As entrevistas individuais foram realizadas em locais e horários definidos pelos colaboradores: com Dom Ramón ocorreu na residência do religioso no dia $1^{\circ}$ de março de 2018 , às 16 horas, com duração de 53 minutos; com Ivanilde foi realizada em sua residência no dia 15 de janeiro de 2019, às 15 horas, com duração de 42 minutos; e com Ecileide foi coletada em seu local de trabalho, ou seja, na coordenação de uma escola particular, às 14 horas do dia 14 de janeiro de 2019, com duração de 36 minutos. A validação das transcrições com a normalista e a professora foram efetivadas no mês de março de 2019 segundo a técnica geradora de estrutura de discurso de Flick (2019), que permite ao entrevistado a leitura da textualização e a possibilidade de ajustes com acréscimos e supressões.

De posse das narrativas, sentiu-se a necessidade de realizar uma pesquisa documental para localizar o regimento interno da instituição, mencionado pelos entrevistados - ainda que sem muita precisão - e outros aportes que pudessem contribuir para a elaboração da narrativa histórica sobre a Escola Normal Helvídio Nunes de Barros. Afinal, o entrecruzamento das fontes orais com aportes documentais possibilitaria ampliar compreensões, já que “[...] a análise documental pode se constituir numa técnica valiosa de abordagem de dados qualitativos, seja complementando as informações obtidas por outras técnicas, seja desvelando aspectos novos de um tema ou problema" (ANDRÉ; LÜDKE, 2012, p. 38).

A pouca documentação preservada da escola que sobreviveu ao cupim e às traças, após a morte do diretor Dom Ramón, foi encaminhada pela Diocese de Bom Jesus para a Secretaria da Educação do estado do Piaú, situada em Teresina (capital do estado), pelo fato de Bom Jesus não possuir arquivo público para a guarda e preservação de documentação de cunho educacional. No arquivo da Secretaria da Educação de Teresina foram localizados apenas os seguintes documentos: a resolução de abertura da escola, um calendário de 1981 e o regimento interno. Esse último foi fonte de fundamental importância para colaborar com a compreensão da história da fundação da instituição.

\section{A Escola Normal: compreendendo contextos}

Importa lembrar que o surgimento do modelo de Escola Normal para formar professores adotado no Brasil remonta ao século XVIII na França, uma vez que foi durante a Revolução Francesa ${ }^{4}$ que começaram a emergir algumas reformas que contribuíram para o desenvolvimento de uma nova maneira de fomentar educação. As ideias iluministas ${ }^{5}$ foram relevantes por impulsionar diversas transformações no cenário educacional da Europa, com "[...] a institucionalização da instrução pública e as contribuições pedagógicas de Comenius, Pestalozzi e outros" (ARAÚJO, 2010, p. 36). A escola deixava de fazer parte da igreja, uma vez que a Europa ainda vivia o teocentrismo e passava a ser regida pelo Estado, ou seja, tornando-se pública. Amparando-se nos ideais iluministas, pautados nos termos "Liberdade, Igualdade e Fraternidade", a escola seria percebida como alavanca fundamental para o desenvolvimento da sociedade, sendo o Estado responsável pela sua manutenção, afinal a sociedade em desenvolvimento precisava de uma educação que atendesse às demandas das mudanças econômicas e políticas ocorridas ao longo

\footnotetext{
${ }^{4}$ A Revolução Francesa (1789-1799) foi um período de intensa agitação política e social na França, que gerou mudanças sociais, políticas e econômicas duradouras na história do país e mais amplamente em todo o continente europeu (GILES, 1987).

5 O Iluminismo, também conhecido como "Século das Luzes", foi considerado um movimento intelectual europeu surgido na França no século XVII. A principal característica dessa corrente de pensamento foi defender o uso da razão sobre o da fé para entender e solucionar os problemas da sociedade (ARAÚJO, 2010).
} 
dos anos. Esse foi também o momento de emergência do positivismo, visto que o referido sistema nasceu de concepções iluministas (HOBSBAWM, 2013).

Pensando na formação dos professores leigos que assumiam a tarefa de educar, Joseph Lakanal (1762-1845), político e administrador francês, no período da Revolução Francesa, instituiu, no dia 30 de outubro de 1794, em Paris, o decreto da criação da primeira Escola Normal na Convenção da França ${ }^{6}$, com o intuito de "[...] defender a formação específica para os professores como instrumento de viabilização da instrução pública nacional" (ARAÚJO, 2010, p. 41). O modelo de educação oferecido pela Escola Normal na França inspirou as instituições de formação de professores no Brasil, a princípio destinadas mais enfaticamente ao público feminino das classes sociais mais abastadas, posteriormente colaborando largamente com a formação de mão de obra para atuar na educação elementar mediante o intento de universalizar a educação primária:

Fica, portanto, evidenciado que a Escola Normal foi um dos instrumentos para o desdobramento da universalização do ensino primário à medida que ia se materializando o novo ideário pedagógico: laico, racional, científico e orientado para os novos valores sociais e civis, preconizados pela Ilustração francesa, e comprometido com a formação de cidadãos úteis e ativos no sentido de atender às novas exigências e interesses social-político-econômico e culturais do Estado Moderno em vias de consolidação. (ARAÚJO, 2010, p. 44).

A Escola Normal teve um papel importante no projeto de universalização do ensino primário no Brasil, não diferente do que ocorreu no estado piauiense, especialmente no que diz respeito à constituição de um novo modelo pedagógico caracterizado como laico, racional e científico. Além disso, também eram ressaltados novos valores que colaboravam com a formação de indivíduos minimamente instruídos e disciplinados, uma vez que precisavam se adequar às novas concepções sociais, políticas e culturais, isto é, o indivíduo precisava se enquadrar nos novos padrões de trabalhador que a modernidade exigia: possuir conhecimentos elementares para ocupar cargos desprestigiados economicamente para os quais se necessitavam a leitura e o desenvolvimento de operações matemáticas básicas, sem consciência crítica suficiente para contestar o modelo de produção e acumulação de capital (OLIVEIRA, 2004).

No Brasil, o Ensino Normal iniciou sua história a partir de 1835, com a primeira Escola Normal, implantada em Niterói:

A primeira iniciativa de criação dessa instituição educacional [...] foi a Escola Normal de Niterói, que deveria servir de modelo às instituições congênitas a serem instaladas nas demais províncias brasileiras. Sua criação foi oficializada através do Ato n. 10 da Assembleia Legislativa da Província do Rio de Janeiro no dia $1^{\circ}$ de abril de 1835, sancionada pelo então presidente provincial, Joaquim José Rodrigues Torres, o Visconde de Itaboraí. (ARAÚJO, 2010, p. 55).

A partir dessa iniciativa, foram surgindo Escolas Normais em outras províncias com o objetivo de formar professores para o ensino elementar, visto que o desenvolvimento educacional do país aconteceria mediante a intervenção de professores que precisavam ser bem preparados. Quanto a esse aspecto, Saviani (2009, p. 144) ressalta:

\footnotetext{
${ }^{6}$ Vale ressaltar que o primeiro conceito de Escola Normal no mundo foi criado por Jean-Baptiste de La Salle, em 1685, com o objetivo de formar os professores do magistério elementar cristão e elaborar normatização para as escolas e para o ofício do professores (ARAÚJO, 2010).
} 
Esse caminho foi seguido pela maioria das províncias ainda no século XIX, na seguinte ordem: Bahia, 1836; Mato Grosso, 1842; São Paulo, 1846; Piauí, 1864; Rio Grande do Sul, 1869; Paraná e Sergipe, 1870; Espírito Santo e Rio Grande do Norte, 1973; Paraíba, 1879; Rio de Janeiro (DF) e Santa Catarina, 1880; Goiás, 1884; Ceará, 1885; Maranhão, 1890. Essas escolas, entretanto, tiveram existência intermitente, sendo fechadas e reabertas periodicamente.

O Ensino Normal chegou ao Piauí, na cidade de Teresina, no ano de 1864, mediante a autorização oficial dada pela Lei Provincial n. 565, de 5 de agosto de 1864, que impulsionou sua instalação, ocorrida em 3 de fevereiro de 1865, bem como a elaboração de seu regulamento, aprovado em 6 de setembro do mesmo ano (SOUSA, 2009). Já o funcionamento da Escola Normal Helvídio Nunes de Barros, primeira Escola Normal do sul do Piauí, objeto desta pesquisa, deu-se em 1970, poucos anos depois da publicação da Lei Provincial, a partir da iniciativa da Ordem Mercedária, principal entidade religiosa responsável pela educação no município de Bom Jesus no final do século XX, como se esclarece na discussão específica sobre esse município, a seguir.

\section{Contextualização do cenário educacional de Bom Jesus-PI}

O município de Bom Jesus se localiza ao extremo sul do Piauí, às margens do Rio Gurgueia, fazendo parte da mesorregião do sudoeste piauiense, assim como da microrregião do Alto Médio Gurgueia, possuindo aproximadamente 30 mil habitantes, dos quais muitos trabalham em atividades relacionadas ao agronegócio ${ }^{7}$ (IBGE, 2018).

Inicialmente Bom Jesus era chamado de Buritizinho, local onde concentrava-se um vasto campo de palmeiras buriti ${ }^{8}$, mas sua nomenclatura foi alterada. Como na maioria dos municípios piauienses, a presença da Igreja Católica foi muito forte na cidade, e um grupo de romeiros, no primeiro quartel do século XIX, ergueu uma capela para adorar Bom Jesus da Boa Sentença, em volta da qual foram se estabelecendo algumas famílias, proporcionando, assim, um crescente desenvolvimento da povoação no local. Com o passar do tempo, o território ficou sendo chamado de Bom Jesus da Boa Sentença, recebendo, em 1938, a designação de Bom Jesus, apenas.

Nos quadros de divisão territorial datados de 31-XII-1936 e 31-XII-1937, bem como no anexo do Decreto Lei Estadual n. 52, de 29 de março de 1938, o município em apreço, já sob designação de Bom Jesus, simplesmente se apresenta constituído, como anteriormente, por um distrito apenas, de igual nome. [...] Dá-se o mesmo nas divisões territoriais do estado, fixadas pelos Decretos-Leis estaduais n. 147, de 15 de dezembro de 1938, e 754, de 30 de dezembro de 1943, para vigorarem, respectivamente, nos quadriênios 19381943 e 1944-1949. (SETUVAL, 1999, p. 7-8).

Entende-se, portanto, que Bom Jesus tornou-se um território independente em 1938, porém apenas se emancipando politicamente em 1948. Na ocasião, o primeiro prefeito foi o senhor Francisco da Cruz Filho (doutor Cruz) e o vice-prefeito João Nepomuceno da Fonceca, com mandato de 21 de abril de 1948 a 31 de janeiro de 1951 (SETUVAL, 1999).

Bom Jesus, na década de 1950, era um município bem pequeno, com poucas casas e ruas, porém servia de referência para os demais municípios da circunvizinhança, por possuir sistema

\footnotetext{
${ }^{7} \mathrm{O}$ agronegócio vem da palavra em inglês “agribusiness" e representa o conjunto de atividades agrícolas e industriais no caminho do campo ao consumidor final. Hoje o agronegócio está entre os maiores geradores de emprego no mundo.

${ }^{8}$ Buriti é uma espécie de planta predominante da Mata dos Cocais, que faz parte da sub-região meio-norte do Piauí.
} 
bancário, profícuo comércio e escola, já que na região sul do Piauí o desenvolvimento dos outros municípios era ainda menor. Com apenas uma escola, fundada em 1930, que ofertava somente o primário ( $2^{\circ}$ a $5^{\circ}$ anos), Bom Jesus galgava destaque, visto que dispunha da "[...] primeira escola gratuita, então chamada Escola Singular Franklin Dória, depois Escola Agrupada Franklin Dória e atualmente Unidade Escolar Franklin Dória" (SETUVAL, 1999, p. 10).

Com a crescente necessidade de a população continuar sua escolarização, a Ordem Religiosa Mercedária entrou em acordo com o poder político local para fundar um Ginásio que atendesse à população com séries mais adiantadas, a fim de suprir a necessidade dos alunos da região de darem continuidade a seus estudos. No ano de 1956, um político, chamado Odilon Parente, doou para a prelazia um espaço grande já construído para que funcionasse a instituição educacional. Em sua homenagem, a escola foi denominada de Ginásio Odilon Parente e iniciou seu funcionamento apenas no turno da manhã, passando depois também a funcionar no turno da tarde, já que o expediente matutino não conseguia atender à demanda reprimida de estudantes do município e seus arredores que almejavam dar continuidade à escolarização. Vale lembrar que o referido Ginásio era de cunho particular e aplicava severo exame de admissão, sendo frequentado pela elite local.

Com o acesso ao Ensino Ginasial, correspondente às séries de $6^{\circ}$ a $9^{\circ}$ anos, a população bonjesuense mais abastada logo começou a sentir a necessidade da continuação da escolarização mediante o curso científico. Em 1970, a prelazia de Bom Jesus, por meio da unidade mantenedora "Obras Sociais do Gurgueia" e da resolução do Conselho Estadual de Educação (CEE) n. 4/1970, fundou a Escola Normal Helvídio Nunes de Barros, objeto deste estudo, na tentativa de solucionar duas demandas: os anseios de alguns jovens pelo prosseguimento nos estudos e a necessidade de o município dispor de professores com o mínimo de preparo profissional para atuar nas escolas que emergiam na região. Por exemplo, em 1972 foi criada a segunda escola primária de Bom Jesus:

Esta instituição iniciou suas atividades de ensino em 12 de maio de 1972, durante o Governo de Alberto Tavares Silva. A escola recebeu este nome em homenagem à senhora Araci Maria Ferreira Lustosa, sendo a primeira professora diplomada no curso magistério da cidade de Bom Jesus (PI). (SOUSA; ANDRADE, 2013, p. 1679).

Observa-se que as demandas, de fato, iam sendo atendidas com o funcionamento da Escola Normal Helvídio Nunes de Barros, pois as professoras diplomadas no Curso Normal ingressavam no magistério das escolas primárias de Bom Jesus.

No ano de 1979, o poder público assumiu a responsabilidade de oferecer Ensino Secundário e fundou o Ginásio Joaquim Parente (nomenclatura em homenagem ao vereador filho de Odilon Parente), com ensino gratuito, que se destacou por sua boa qualidade no ensino. Em decorrência, extinguiu-se o Ginásio Odilon Parente, uma vez que o mesmo era de cunho particular, e a população preferia estudar em estabelecimento renomado sem custos. Dessa maneira, a escola que deveria beneficiar os alunos que não tinham condições necessárias para financiar seus estudos acabou por abarcar toda a demanda da região, privilegiando, mais uma vez, os mais abastados.

Inicialmente em 1979, a escola (Ginásio Odilon Parente) funcionava dois turnos, manhã e tarde, de $5^{\mathrm{a}}$ a $8^{\mathrm{a}}$ série (atual $6^{\circ}$ a $9^{\circ}$ ano). Devido à inauguração dessa nova escola (Ginásio Joaquim Parente), os alunos tiveram mais oportunidades para estudar e não teriam a necessidade de irem para outras cidades ou mesmo pagarem uma escola particular mesmo sem terem recursos suficientes. (SOUSA, R.; SOUSA, W.; ANDRADE, 2016, p. 7). 
Somente em 1982, criou-se outra instituição de Ensino Secundário em Bom Jesus, o Colégio Agrícola de Bom Jesus, no qual funcionavam os Ensinos Primário e Secundário com o Ensino Técnico em Agropecuária. A partir de então, foram emergindo outras instituições escolares de cunho municipal e estadual, pois a demanda por educação aumentava cada vez mais com o crescimento populacional e o desenvolvimento do comércio. E era a Escola Normal Helvídio Nunes de Barros que supria a maior parte da mão de obra para a atuação nesses estabelecimentos educacionais, já que era o único Curso Normal da região.

\section{História e memória da fundação da Escola Normal Helvídio Nunes de Barros}

A primeira Escola Normal de Bom Jesus teve autorização para seu funcionamento em 27 de fevereiro de 1970 pelo CEE mediante a resolução de n. 4/1970. Na década de 1970, o Brasil passava pela ditadura militar, período de intensas transformações em diversos setores, como: político, econômico e também educacional. Nessa época, na região sul do Piauí, especificamente em Bom Jesus, em relação ao contexto educacional, crescia o número de discentes que concluíam o ensino secundário, sendo necessária uma instituição que atendesse ao ensino de $2^{\circ} \mathrm{Grau}$.

Pioneira no Ensino Normal em Bom Jesus, a Escola Normal Helvídio Nunes de Barros recebeu este nome em decorrência da amizade que o bispo daquela época, Dom José Vázquez Díaz, tinha com o senador Helvídio Nunes de Barros e de sua crença de que o referido político viesse a ajudar na manutenção da escola, ainda que a pretensão inicial fosse mantê-la por meio de recursos arrecadados com obras sociais, como explicita seu regimento interno nos artigos $1^{\circ}$ e $2^{\circ}$ :

A Escola Normal Helvídio Nunes de Barros é uma instituição educativa, confessionalmente católica, institucionalmente apolítica, com objetivo de dar a seus alunos formação integral, a fim de prepará-los para o perfeito conhecimento de seus deveres com Deus, a Igreja e a Pátria. A Escola Normal Helvídio Nunes de Barros tem como entidade mantenedora as Obras Sociais do Gurgueia - entidades de fins filantrópicos a caráter beneficente, educativo, cultural e da assistência social.

De natureza filantrópica, a escola não dependia diretamente de recursos estaduais ou municipais, prevendo em seu regimento educação apolítica, ou seja, que não envolvesse a educação com questões políticas, inclusive se abstendo de problematizar o cenário político ditatorial brasileiro, caracterizado pela repressão, recessão e cerceamento de liberdades individuais (MARTINS, 2009). Tal educação, segundo Freire (2008), não possibilitava um ensino contextualizado, o desenvolvimento da consciência crítica e a formação de sujeitos envolvidos com a transformação da sociedade.

A proposta de formação integral era fomentada por meio dos princípios da religião católica, com foco nas obrigações individuais, e não nos direitos, em especial primando pelo perfeito conhecimento de seus deveres com Deus, a igreja e a pátria. Em outros termos, consoante as ideias nacionalistas difundidas no Brasil na década de 1970, a escola primava pelo ensino técnico e os deveres com o patriotismo (MARTINS, 2009).

Ao longo de sua trajetória, a Escola Normal Helvídio Nunes de Barros teve três localizações distintas: a primeira era sediada em cima da catedral, em frente à Praça Sete de Setembro, sem número, que se localizava no centro da cidade, na qual permaneceu até 1990; a segunda era localizada na rua Arsênio Santos, número 415; e a terceira localização permaneceu nessa mesma rua, mas no numeral 437, sendo todos os prédios de posse da diocese.

\footnotetext{
${ }^{9}$ Regimento elaborado pelo CEE do Piauí em 1971.
} 
Considerando que o objetivo da pesquisa foi compreender sua fundação, na década de 1970, centrou-se ênfase no período da sua primeira edificação.

A Escola Normal Helvídio Nunes de Barros, nas suas primeiras décadas de funcionamento, situando-se no segundo andar da catedral, destinava-se a ministrar o ensino profissional com curso de magistério em consonância com as diretrizes da Igreja Católica para a formação de alunos caridosos, tementes a Deus e vocacionados à profissão docente. A escola não fazia parte da rede municipal ou estadual e os seus alunos deveriam pagar uma taxa de mensalidade para assegurar sua permanência, com a alegação de que as doações não eram suficientes para sua manutenção. A supervisora da escola explicou: "Era escola de padres; era da diocese; e era praticamente gratuita; era um pagamento simbólico, só para manutenção ali, porque aqui não tinha $2^{\circ} \mathrm{Grau}$, e isso repercutia nos vestibulares" (BORGES, 2019).

Importa refletir acerca da oralidade citada, afinal, na década de 1970, em Bom Jesus, não eram muitos os alunos que podiam deixar de colaborar com os afazeres domésticos e com a agricultura para se dedicarem aos estudos, especialmente podendo dispor de orçamento familiar para pagar as taxas da escola. Tal situação acabava por tornar a instituição frequentada principalmente por filhos das elites locais, sobretudo porque a escola adotava exames para o ingresso dos estudantes. Essas características elitistas e segregacionistas não diferem de parte considerável das Escolas Normais no início de suas atividades no Brasil (MARTINS, 2009).

Quanto à matrícula dos educandos, eram realizadas pelos pais ou responsáveis, ou pelo próprio aluno, se possuísse a maioridade. Para o efeito da matrícula, destaca-se a determinação do artigo 31 do regimento interno:

Apresentação da documentação que assegura ao aluno o direito de iniciar ou prosseguir os estudos na série em que pretende matricular-se; a critério da Direção, o candidato pode ser submetido a um exame, caso o resultado desta seja considerado insatisfatório a matrícula pode ser recusada; não haverá renovação automática da matrícula, devendo o aluno promovido, através de seu responsável ou por si mesmo, se maior, requerer a matrícula, dentro do prazo previsto.

À luz das instruções do regimento interno da instituição, pode-se perceber o rigor em relação à matrícula dos alunos na Escola Normal mediante o exame de admissão, ao mesmo tempo a brecha para o apadrinhamento e sua dispensa a critério da direção. O que importa destacar é que na prática o exame de admissão foi amplamente adotado nos primeiros anos de seu funcionamento; posteriormente, com a diminuição da procura pela Escola Normal, ele foi suspenso, como ressaltou a supervisora: "[...] no começo tinha, depois parou de ter, mas no começo tinha o teste porque a procura pela escola era grande" (BORGES, 2019).

A administração da escola, segundo o artigo $5^{\circ}$ de seu regimento, era feita por um diretor “[...] devidamente qualificado para o exercício da função, que deverá presidir o funcionamento dos serviços escolares, o trabalho dos professores e alunos e as relações da escola com a comunidade". No tocante ao corpo docente, os professores precisavam ser habilitados para o exercício do magistério de acordo com a lei que regulava a matéria, no caso a Lei n. 5.692/1971, que assinalava:

A formação de professores e especialistas para o ensino de $1^{\circ}$ e $2^{\circ}$ graus será feita em níveis que se elevem progressivamente, ajustando-se às diferenças culturais de cada região do País, e com orientação que atenda aos objetivos específicos de cada grau, às características das disciplinas, áreas de estudo ou atividades e às fases de desenvolvimento dos educandos. 
Gestor e professores seguiam a estrutura curricular da Escola Normal de Bom Jesus, elaborada de acordo com o seu Regimento Interno (1971), funcionando da seguinte maneira: "O currículo, como conjunto de todas as experiências sob a responsabilidade do estabelecimento, será organizado pelo Diretor, em equipe com os Orientadores Pedagógicos e o Corpo Docente do Estabelecimento". Na prática, o currículo era organizado pelo gestor, classificando por função, uma forma hierárquica das instituições escolares. O calendário escolar, segundo o regimento interno (1971), possuía 180 dias letivos dedicados às atividades escolares, que eram elaborados a cada ano, antes do início das aulas, pela orientação pedagógica, podendo sofrer alterações apenas se indicadas pela direção da escola, que deveria assegurar a carga horária mínima de 2.200 horas de trabalho para o Ensino Médio (antigo $2^{\circ}$ Grau). O regimento interno da instituição, orientado pela Lei n. 5.692/1971, em seu artigo 11, apontava que "[...] o ano e o semestre letivos, independentemente do ano civil, terão, no mínimo, 180 e 90 dias de trabalho escolar efetivo, respectivamente, excluído o tempo reservado às provas finais, caso estas sejam adotadas".

Em relação à avaliação de aprendizagem, esta era quantificada e expressa em notas de 0 a 10, com média de 5 pontos, como apresenta o artigo 50 do regimento interno: "Para ser promovido de série, o aluno deverá obter, pelo menos nota 5 (cinco) como nota final em todas as atividades, áreas de estudo ou disciplinas".

No tocante às disciplinas ministradas na instituição, eram divididas em Educação Geral e Formação Especial. As disciplinas que compunham o currículo da Educação Geral eram: Língua Portuguesa e Literatura Brasileira, Língua Estrangeira (inglês), Educação Física, Educação Artística, Geografia, História, Organização Social e Política Brasileira (OSPB), Educação Moral e Cívica (EMC), Matemática, Biologia, Física, Química e Ensino Religioso. Já as da Formação Especial consistiam em: Redação e Expressão, Literatura Infantil, Artes Infantis, Fundamentos Psicológicos, Fundamentos Sociológicos, Fundamento da Filosofia, Complemento da Matemática, Administração Escolar, Didática, Metodologia da Língua Pátria, Práticas de Ensino e Estágio Supervisionado.

Dentre as disciplinas já mencionadas, como não poderia faltar em instituição educacional pertencente à Igreja, a Escola Normal Helvídio Nunes de Barros valorizava as aulas de Ensino Religioso, acrescentando atividades como as missas comunitárias e festivais religiosos, às quais a direção convidava a comunidade para assistir, juntamente com todos os alunos uniformizados, transmitindo a imagem de que a escola tinha disciplina e boa organização. O ex-professor suavizou o rigor disciplinar ao afirmar: "Havia aula de religião, missas comunitárias com todos os alunos, algumas missas, algumas outras festividades religiosas que exigiam comparecer todos os alunos uniformizados, mas não era assim uma coisa muito imposta, muito séria, era mais um convite" (CARROZAS, 2018).

Em entrevista com uma ex-aluna, Ecileide Martins, ao contrário do relato do professor, ela relembrou a dinâmica do funcionamento da instituição, caracterizando-a como "[...] tradicionalista, disciplinadora e rigorosa no uso do fardamento":

A gente tinha a farda, o uniforme seria a saia no joelho, a blusa de manga e golinha, tinha que passar a blusa por dentro da saia e colocar o cinto, tênis não, sapatinho preto e meia, e essa meia ela era longa, no joelho, às vezes a gente até colocava aquela ligazinha para a meia não descer, para ela ficar naquele lugar, era tipo assim: a saia praticamente encontrando com a meia, era naquele cumprimento ali. Então todos eram nesse sentido, a blusa branca e a saia ela era assim um marrom, bege. (MARTINS, 2019). 
A ex-aluna contou com ricos detalhes sobre o fardamento da instituição e explicou que tal exigência era imprescindível para o acesso à escola. Além disso, a ex-aluna ainda relatou que as salas eram superlotadas, justificando a situação pelo fato de a Escola Normal Helvídio Nunes de Barros ser a única existente no sul do Piauí:

As turmas eram lotadíssimas, acho que eram 40, 40 e poucos alunos, porque as salas lá da Escola Normal eram salas muito grandes e elas eram lotadas, porque toda essa região de Manuel Emídio, de Elizeu Martins, Colônia, Palmeiras, Redenção, todo mundo estudava aqui. (MARTINS, 2019).

Ademais da severa disciplina e da valorização do Ensino Religioso, outro ponto que não se pode deixar de abordar é a importância que a escola dava às disciplinas de OSPB e EMC. Havia a exacerbada valorização da pátria, percebida desde a relevância ensejada ao desfile do dia 7 de setembro, que era considerado um marco histórico: "[...] era a coisa mais linda. Aliás, eram as escolas daqui todas reunidas, sempre faziam todas, era a coisa mais linda, eu acho que eu não tive oportunidade de ver nenhum desfile tão lindo como os de Bom Jesus em lugar nenhum" (BORGES, 2019).

Essa supervalorização do patriotismo estava relacionada ao regime militar no Brasil, que durou 21 anos (1964-1985), ou seja, como a Escola Normal Helvídio Nunes de Barros foi fundada em 1970, em tempos de ditadura, quando era comum exaltar o civismo e o amor à pátria em todas as escolas, a comemoração ao dia 7 de setembro era a fiel representação dessa valorização. A Escola Normal visava à formação de professores que transmitissem o amor incondicional à pátria numa perspectiva apolítica, na qual não se contestava o regime político, ao contrário, exaltava-se a necessidade de obediência e subserviência.

As disciplinas OSPB e EMC não foram implantadas nas escolas por acaso, porque havia uma intencionalidade subjacente, já que a ideia que pairava no país durante a ditadura era congruente ao enquadramento do comportamento das pessoas dentro de um padrão social, que estava sendo construído pelo Estado, de apatia e silenciamento, para não fomentar as manifestações contrárias ao regime autocrático. Por meio de desfiles cívicos, respeito à Bandeira Nacional, canto do Hino Nacional no início das aulas, dentre outras atividades, desenvolvia-se o patriotismo (ABREU; INÁCIO FILHO, 2006).

O regime ditatorial brasileiro, de maneira direta ou indireta, repercutia na educação de Bom Jesus mediante as práticas que eram impostas na escola, em contraposição a uma proposta de educação humanizadora, emancipadora e democrática (ARAÚJO; SANTOS, 2014), pois a proposta de educação era sustentada pelo modelo tradicional de ensino, tendo como base o tecnicismo e as práticas educativas caracterizadas por operações mnemônicas, descontextualizadas e estáticas. Segundo Luiz Júnior (2013, p. 35), “[...] a pedagogia tecnicista da década de 60-70 esforçou-se para tirar o foco de atuação da escola, das questões sociais, deslocando-o para os problemas de aprendizagens, métodos e técnicas de ensinar".

Ainda que emergentes em cenários antidemocráticos, muitas Escolas Normais no Brasil fomentaram marco na História da Educação Brasileira no que concerne ao pioneirismo na instrução específica para a formação de professores, e a Escola Normal Helvídio Nunes de Barros foi uma instituição que contribuiu significativamente para a formação de professores não só no município de Bom Jesus, mas também em todo o sul do Piauí, por ser a única escola dessa modalidade na região, como relatou Borges (2019):

Era porque aqui no sul do Piauí não tinha o magistério e era muito boa a escola nos seus primeiros anos. [...] se manteve em Bom Jesus quando Bom Jesus precisava, porque não tinha $2^{\circ} \mathrm{Grau}$, depois veio o colégio agrícola, colégios particulares, ela passou a ser pouco necessária, e acho que por isso foi extinta. 
Constata-se, com as palavras da entrevistada, a importância da Escola Normal Helvídio Nunes de Barros para a qualificação docente, principalmente nos primeiros anos de sua implantação, visto que a região não contava com nenhuma escola para a formação de profissionais para a atuação no magistério, tampouco escolas com o ensino científico.

Com duração de 31 anos de funcionamento (1970 até 2001), a Escola Normal de Bom Jesus deixou como um de seus legados centenas de profissionais formados para o exercício do magistério. A referida instituição teve seu fechamento por inúmeras razões, a principal delas foi a ação governamental de universalização do Ensino Secundário com a implantação no interior do estado do Piauí de várias escolas públicas descentralizadas com essa etapa da educação no fim do século XX.

$\mathrm{O}$ estado abriu por essas épocas muitos $2^{\circ}$ Graus, até no interior! Em todas as cidades, porque, no tempo da Escola Normal, $2^{\circ}$ Grau não havia em toda região, praticamente só aqui, então tinha muito aluno, mas, quando o estado começou a abrir $2^{\circ}$ Grau aqui e acolá, diminuiu muito o número de alunos, até que chegou a ter só uma matrícula em um ano, aí tivemos que suspender. (CARROZAS, 2018).

Carrozas explicitou como se deu a extinção da Escola Normal de Bom Jesus, pois, mesmo que a demanda de aprendizes fosse crescente a cada ano para acesso ao Ensino Secundário, o estado começou a implantá-lo gratuitamente nas comunidades mais afastadas da cidade a partir do final do século XX. Assim sendo, a população circunvizinha não precisava mais se deslocar para Bom Jesus em busca de escolarização e a população local já possuía outras opções para o prosseguimento nos estudos. Segundo o Bispo Dom Ramón Carrozas (2018), "No ano de 2001 a Escola Normal contou apenas com uma nova matrícula, chegando ao ponto de não ter recursos suficientes para manter os salários dos professores que ali estavam". Então, nesse mesmo ano, a Escola Normal Helvídio Nunes de Barros de Bom Jesus foi fechada, permanecendo no imaginário social de muitos moradores de Bom Jesus.

\section{Considerações finais}

A pesquisa versou sobre a fundação da primeira Escola Normal da região sul do Piauí e sua inter-relação indissociável com o contexto educacional de Bom Jesus da década de 1970. Em congruência com essa temática, como problema propulsor para a realização do estudo, questionou-se como se deu a constituição da Escola Normal Helvídio Nunes de Barros no contexto educacional de Bom Jesus. Para responder à inquietação, desenvolveu-se uma pesquisa científica, de perspectiva micro-histórica, que utilizou o percurso metodológico da História Oral Temática entrecruzando as fontes orais - de dois ex-profissionais e de uma ex-aluna - com as documentais - regimento interno e resolução consoante a fundação da Escola Normal.

O estudo permitiu refletir que as Escolas Normais tiveram um crescimento gradativo em todo o Brasil desde 1835, sendo este o ano de implantação do Ensino Normal no país, que emergiram à luz do modelo francês. No entanto, no tocante ao estado do Piauí, o Ensino Normal somente foi iniciado em 1864 na capital do estado, Teresina, quase 30 anos depois da implantação da primeira Escola Normal na Bahia, em 1836. Em Bom Jesus, principal cidade do sul do Piauí à época, a formação de professores se iniciou ainda mais tarde, apenas em 1970.

A Escola Normal Helvídio Nunes de Barros foi a primeira Escola Normal do sul do Piauí, implantada em Bom Jesus. Até 1970, a educação da região sul do estado era ministrada basicamente por professores leigos, pois raros eram os docentes que se deslocavam da capital para trabalhar em Bom Jesus. A Escola Normal Helvídio Nunes de Barros foi fundada por meio 
de iniciativas da Igreja Católica, mais especificamente pela mediação do Bispo Dom José Vázquez Díaz, por intermédio das "Obras Sociais do Gurgueia”, como principal organização mantenedora da instituição, desde doações.

Como havia a alegação de que as doações não eram suficientes para arcar com todos os gastos da Escola Normal, cobravam-se taxas - matrícula e mensalidades -, que não eram acessíveis a boa parte da população da região. Em decorrência, a escola atendia prioritariamente à elite da região, já que os menos abastados se dedicavam às tarefas domésticas e à agricultura e não podiam dispor de tempo livre para a escolarização, tampouco de recursos para custear as taxas cobradas, o material didático e o fardamento exigido.

Não fosse o bastante a exclusão fomentada pela renda, também havia uma rigorosa seleção, baseada nos conhecimentos prévios, efetivada mediante o teste de admissão, para o qual somente conseguiam êxito os alunos que haviam frequentado um bom Ensino Primário. Importa relembrar que até 1957 não havia Escola de Ensino Secundário, pois o Ginásio havia sido fundado em 1958, e este era o único estabelecimento com essa oferta até 1973, quando foi implantada a primeira escola pública com o Ensino Secundário gratuito.

Vinculada à Igreja Católica, a Escola Normal Helvídio Nunes de Barros seguiu o modelo tradicional de ensino, caracterizado pela autoridade centralizada no professor e valorização da obediência, fomentando conhecimento mediante operações mnemônicas descontextualizadas em consonância com os princípios cristãos da igreja e com o patriotismo característico do período ditatorial. Havia um severo controle quanto ao uso do uniforme, à disciplina e à pontualidade, especialmente em atividades como as missas comunitárias, hasteamento da bandeira e desfiles cívicos, nos quais se apresentava a escola para a comunidade.

Pautada em uma educação "apolítica", a Escola Normal Helvídio Nunes de Barros, em seus primeiros anos de funcionamento, foi marcada por uma educação elitista que reproduzia os valores socioculturais da elite local, segundo um ensino bancário que contemplava dois blocos de disciplinas: Educação Geral e Formação Especial. O primeiro trabalhava disciplinas de conhecimentos mais amplos e o último lidava com disciplinas voltadas para o magistério. Todavia, havia uma supervalorização do Ensino Religioso, da OSPB e da EMC, disciplinas que transmitiam, respectivamente, os valores da Igreja e do Estado, sempre com foco nos deveres do cidadão, e nunca nos seus direitos.

Com a finalidade de formar professores marianos, tementes a Deus e às autoridades e amantes da pátria, a formação para o magistério era dispensada de maneira acrítica, corroborando o modelo de sociedade vigente: segregacionista, excludente e desigual. A instituição só teve seu declínio em 2001, a partir da fundação de outras instituições educacionais, com finalidade semelhante, de caráter público, ou seja, quando o Ensino Secundário foi sendo universalizado e assumido pelo estado e a população do sul do Piauí já não era obrigada a arcar com os altos custos da Escola Normal Helvídio Nunes de Barros para galgar essa etapa da escolarização.

Ainda que com caráter elitista, especialmente nos seus primeiros anos de funcionamento, a Escola Normal Helvídio Nunes de Barros funcionou durante 31 anos, sendo a instituição responsável pelo desenvolvimento educacional da região sul do Piauí por meio da formação de professores. Afinal, foram aproximadamente três décadas em que essa escola atuou como única instituição com essa finalidade na região.

O estudo das instituições escolares permite conhecer e ampliar a compreensão acerca da história da educação de um determinado local. Nesse sentido, através da história e da memória da fundação de uma Escola Normal, foi possível partir do micro, a Escola Normal Helvídio Nunes de Barros, para discutir o macro, o contexto educativo de Bom Jesus, desde o alargamento do entendimento do que se pode considerar como fonte histórica, particularmente a partir da perspectiva teórica da História Cultural. 
Importa inferir que este estudo lança mão de uma narrativa histórica que não se pretende universalizante, generalista ou inquestionável, ao contrário, traz uma reflexão acerca da educação que era vivenciada no final do século XX na região sul do Piauí, realidade sobre a qual há ainda muito a ser investigado. Espera-se que outras pesquisas possam lançar luz à cidade de Bom Jesus e à região sul do Piauí, ainda pouco explorada no âmbito da História da Educação, colaborando para problematizar a história e a memória da Educação Brasileira.

\section{Referências}

ABREU, G.S.A.; MINHOTO, M.A.P. Política de admissão ao ginásio (1931-1945): conteúdos e forma revelam segmentação do primário. Revista Histedbr, Campinas, n. 46, p. 107-118, 2012. https://doi.org/10.20396/rho.v12i46.8640074

ABREU, V.K.; INÁCIO FILHO, G. A educação moral e cívica - doutrina, disciplina e prática educativa. Revista Histedbr, Campinas, n. 24, p. 125-134, 2006.

ALBERTI, V. Manual de História Oral. 3. ed. Rio de Janeiro: FGV, 2005.

AMADO, J.; FERREIRA, M.M. Usos e abusos da História Oral. 8. ed. Rio de Janeiro: FGV, 2006.

ANDRÉ, M.E.D.; LÜDKE, M. Pesquisa em educação: abordagens qualitativas. São Paulo: EPU, 2012.

ARAÚJO, P.C.A.; SANTOS, J.M.C.T. Prática docente e currículo de História: considerações a partir da memória de professores no contexto da ditatura militar. In: SANTANA, J. R. et al. (Org.). Golpe de 1964: História, geopolítica e educação. Fortaleza: UECE, 2014. p. 91-111.

ARAÚJO, R.M.S. Escola Normal na Parahyba do Norte: movimento e constituição da formação de professores no século XIX. 2010. 319 f. Tese (Doutorado em Educação) - Programa de PósGraduação em Educação, Universidade Federal da Paraíba, João Pessoa, 2010.

BRASIL. Lei n. 5.692, de 11 de agosto de 1971. Fixa Diretrizes e Bases para o Ensino de $1^{\circ}$ e $2^{\circ}$ Graus, e dá outras providências. Diário Oficial [da] República Federativa do Brasil, Poder Executivo, Brasília, DF, 12 ago. 1971.

BURKE, P. A Escola dos Annales (1929-1989): a revolução francesa da historiografia. 2. ed. São Paulo: Unesp, 2010.

FIALHO, L.M.F.; SA, E.C.V. Educadora Henriqueta Galeno: a biografia de uma literata e feminista (1887- 1964). História da Educação, v.22, p.169-188, 2018. Disponível em: https://seer.ufrgs.br/asphe/article/view/75182. Acesso em: 13 fev. 2020. https://doi.org/10.1590/2236-3459/75182

FLICK, U. Introdução à pesquisa qualitativa. 3. ed. São Paulo: Artmed, 2009.

FREIRE, P. Educação e mudança. 31. ed. São Paulo: Paz e Terra, 2008. 
GATTI JR., D. A história das instituições educacionais: inovações paradigmáticas e temáticas. In: ARAÚJO, J.C.S.; GATTI JR., D. (Org.). Novos temas em História da Educação Brasileira: instituições escolares e educação na imprensa. Campinas: Autores Associados; Uberlândia: UFU, 2002. p. 3-24.

GILES, T. R. História da Educação. São Paulo: EPU, 1987.

HALBWACHS, M. A memória coletiva. São Paulo: Centauro, 1993.

HOBSBAWM, E. Sobre História. São Paulo: Companhia das Letras, 2013.

IBGE - Instituto Brasileiro de Geografia e Estatística. Educação de Bom Jesus. 2018. Disponível em: <https://cidades.ibge.gov.br/brasil/pi/bom-jesus/panorama>. Acesso em: 22 jun. 2019.

LE GOFF, J. História e memória. São Paulo: Unicamp, 1996.

LUIZ JR., C. A história da formação de professores no Brasil: análise crítica das políticas de formação por vídeo. 2013. 124 f. Tese (Doutorado em Educação) - Programa de Pós-Graduação em Educação Brasileira, Pontifícia Universidade Católica de São Paulo, São Paulo, 2013.

MAGALHÃES, J. A história das instituições educacionais em perspectiva. In: GATTI JÚNIOR, D.; INÁCIO FILHO, G. (Org.). História da educação em perspectiva: ensino, pesquisa, produção e novas investigações. Campinas: Autores Associados; Uberlândia: UFU, 2005. p. 91-103.

MARTINS, Â.M.S. Breves reflexões sobre as primeiras Escolas Normais no contexto educacional brasileiro, no século XIX. Revista Histedbr, Campinas, n. 35, p. 173-182, 2009. https://doi.org/10.20396/rho.v9i35.8639621

NOVO, B.N. A biografia de Dom José Vázquez Díaz. 2017.

OLIVEIRA, D.G. Memórias e representações acerca da Escola Normal de Juiz de Fora. Cadernos de História da Educação, Uberlândia, v. 3, p. 85-95, 2004.

PIAUÍ. Regimento Interno da Escola Normal Helvídio Nunes de Barros. Teresina: Conselho Estadual de Educação, 1970.

PIAUÍ. Resolução n. CEE/04/70, de 27 de fevereiro de 1970. Teresina: Conselho Estadual de Educação do Piauí, 1970.

POLLAK, M. Memória, esquecimento, silêncio. Estudos Históricos, Rio de Janeiro, v. 2, n. 3, p. 3-15, 1989.

RAPOSO, F.C. História da Paróquia de Bom Jesus da Boa Sentença. Teresina: Ilustradas, 2004.

SANFELICE, J.L. História, instituições escolares e gestores escolares. Revista Histedbr, Campinas, n. especial, p. 20-27, 2006.

SAVIANI, D. Formação de professores: aspectos históricos e teóricos do problema do contexto brasileiro. Revista Educação Brasileira, Brasília, DF, v. 14, n. 40, p. 143-155, 2009. https://doi.org/10.1590/S1413-24782009000100012 
SETUVAL, C.A.R. Evolução política do município de Bom Jesus-PI. Bom Jesus: Câmara Municipal de Bom Jesus, 1999.

SOUSA, J.B. Ser e fazer-se professora no Piauí no século XX: a história de vida de Nevinha Santos. 2009. 236 f. Tese (Doutorado em Educação) - Programa de Pós-Graduação em Educação, Universidade Federal de Uberlândia, Uberlândia, 2009.

SOUSA, R.P.; ANDRADE, M. A. F. S. Escola Araci Lustosa (Bom Jesus-PI): um olhar sobre sua história. In: ENCONTRO CEARENSE DE HISTÓRIA DA EDUCAÇÃO, 12., 2013, Fortaleza. Anais... Fortaleza: UFC, 2013. p. 1675-1685.

SOUSA, R.P.; SOUSA, W. A. ANDRADE, M. A. F. S. Revisitação histórica das instituições escolares de Bom Jesus-PI na década de 70. In: CONEDU, 3., 2016, Natal. Anais... Natal: Conedu, 2016. p. 1-10.

SOUZA, S.T.; LIMA, G.A.P. Escolas polivalentes na ditadura civil-militar: marco no modelo de ensino profissionalizante ou instrumentos de propaganda do regime? O processo de implantação do polivalente de Ituiutaba-MG (1974-1985). Educação \& Formação, Fortaleza, v. 1, n. 2, p. 72-88, 2016.

TEIXEIRA, V.C. Fé e cultura barroca sob o manto mercedário: hierarquias, devoções e sociabilidade a partir da irmandade de Nossa Senhora das Mercês de Mariana. 2017. 220 f. Dissertação (Mestrado em História) - Programa de Pós-Graduação em História, Universidade Federal de Juiz de Fora, Juiz de Fora, 2017. https://doi.org/10.22478/ufpb.2317$\underline{6725.2017 \mathrm{v} 37 \mathrm{n} 37.33814}$

VASCONCELOS, L.M.; FIALHO, L.M.F.; MACHADO, C.J.S. Facetas da (im)potência viril na Revista Careta: educação e masculinidades no Estado Novo (1937-1945). Acta Scientiarum: Education, Maringá, v. 40, n. 4, p. 3-12, 2018. https://doi.org/10.4025/actascieduc.v40i4.41145

\section{Fontes orais}

BORGES, I.F. Entrevista de Ivanilde Felício Borges. Entrevista concedida a Maria Aparecida Alves da Costa. Bom Jesus, 15 de janeiro de 2019, 42 min.

CARROZAS, B.D.R.L. Entrevista de Bispo Dom Ramón López Carrozas. Entrevista concedida a Ademir Martins de Oliveira. Bom Jesus, $1^{\circ}$ de março de 2018, 53 min.

MARTINS, M.E.R.A. Entrevista de Maria Ecileide Ribeiro de Almeida Martins. Entrevista concedida a Maria Aparecida Alves da Costa. Bom Jesus, 14 de janeiro de 2019, 36 min. 